\title{
Project Networks and Changing Industry Practices - Collaborative Content Production in the German Television Industry
}

\author{
Arnold Windeler, Jörg Sydow
}

Arnold Windeler

Institute of

Sociology,

Technical

University of

Berlin, Germany

Jörg Sydow

Department of

Economics and

Business

Administration,

Free University of

Berlin, Germany

\begin{abstract}
Changing industry practices and forms of production organization are the medium and result of co-evolutionary processes of change. The disruptive event of transforming the German TV industry into a dual system triggered a change in content production from in-house to collaborative forms in project networks which are not only highly sensitive to previous and anticipated project practices, but also to industry practices. In turn, the change in the production organization recursively influences the reproduction of industry practices. The co-evolutionary analysis is based on structuration theory.
\end{abstract}

Descriptors: organizational fields, networks, relations, evolution, structuration theory, project management

\section{Introduction}

'Content is king', is a well-known saying in the dramatically changing television industry. One aspect of change is the increasingly global character of this industry, another is the digitalization of its technologies, a third is the privatization of broadcasting in many European countries. The ongoing globalization of the TV industry can best be observed in numerous cross-border mergers, acquisitions and alliances which affect financing, production and distribution, as well as many cultural and production-related aspects, such as programme formating. In fact, most media groups now act as multinational enterprises and control not only the distribution, but also large parts of the content production on a global scale. The digitalization of this industry is symbolized by the adoption of digital technologies for production (AVAD, digital camera) as well as for distribution (DVB, Internet). Both content production and its distribution seem to be more or less equally affected by this development. The ongoing privatization is a third aspect of the changing TV industry, at least in Europe, where public broadcasters now face severe competition from private channels. Privatization drives the TV landscape in several European countries, among them Germany, towards a 'dual system', i.e. an industry which comprises both powerful public and private broadcasters that compete on the demand
Organization

Studies

2001, 22/6

1035-1060

(C) 2001 EGOS

0170-8406/01

$0022-0033 \$ 3.00$ 
side for viewers and advertisers, and on the supply side for terrestrial, cable and satellite channels, and - last but not at all least - for content. Given the dramatic increase in the number of TV channels, which is not only a medium but also a result of the globalization, digitalization and privatization of this industry, content will not only remain king but will, most likely, become an even more critical resource for success in economic (and, perhaps, cultural) terms. Producers, in turn, have to be able to produce content that has to be either entertaining or informative (or both), original, innovative, striking and, not least importantly, to be delivered on time. For quite some time now, content for TV has been produced in projects, under the auspices of producers, by more or less independent authors, directors, actors, cameramen, special effects experts, casting agencies, actors, composers, script consultants, cutters, location scouts, stage designers, grips, etc. Such flexible project-oriented arrangements, which we refer to as project networks, enable producers to deal with the permanently changing demands of broadcasters and stations. At the same time, they provide the necessary social (networked) context which supports project coordination and contributes to successful completion of the projects.

This paper tries to explain how this network form of collaborative content production has evolved in the German TV industry. In some respects, the development of TV in Germany has followed the same evolutionary path as that of the U.S. film industry, where the network form of production emerged from the disaggregation of the Hollywood studio system (Storper and Christopherson 1987; Storper 1989; Robins 1993). Rather then just trying to reconstruct the emergence of network organizations in this industry, the main focus of the present inquiry is on how the evolution of this organizational form is related to the change in practices of the TV industry. The relatedness of network and industry practices is not only relevant to the emergence of this (then) new organizational form, but also to its present functioning. Looking at how changing structures and practices within an industry influence coordination in project networks, and how this form of coordination, in turn, influences the development of industry structures and practices means that we are studying the co-evolution of industry and organizational form (McKelvey 1997; Lewin and Koza 1998). The German TV industry is particularly well-suited to such a co-evolutionary analysis since it has been hit by several 'disruptive events' (Hoffmann 1999), such as the move towards the dual system. It is events such as these, that make it possible for this topic to be studied.

The empirical data for this analysis were collected between 1998 and 2000 in semi-structured interviews with mainly producers and managing directors of 16 major production firms, and with programme editors and executives of the four broadcasting stations situated in the two main 'media' regions of Germany - Berlin and Cologne. ${ }^{1}$ Additionally, providers of artistic and technical media services, funding and development agencies, and other experts contributing to the industry were interviewed. These latter interviews enabled us to cross-check most findings. In total, about 70 interviews were conducted, each taking an average of 2.5 hours, focusing 
mainly on the organization of projects, the integration of the customer (i.e. the broadcaster) and the - in part joint - efforts to coordinate and control the production process (Windeler et al. 2000). However, the interviews also revealed, on the one hand, the interrelationships of structures within the industry and these efforts at coordination and control, on the other. Despite this empirical background, the emphasis of this paper lies on the conceptual level. To understand the constitution of the industry, we emphasize that it should be viewed as a multi-level process based on the recursive interplay of industry processes with practices of production organization.

In terms of theory, and in contrast to most other co-evolutionary analyses, this study follows a qualitative network perspective which is based upon structuration theory (Giddens 1984). ${ }^{2}$ Before this perspective is introduced, the fundamental argument of two prominent perspectives on industry and industrial change will be discussed. This discussion will lead towards a plea for a more integrative, balanced and co-evolutionary analysis of industry and industry change, which - like a structurationist perspective acknowledges and conceptualizes the recursive interplay between industry structures, on the one hand, and organizational form, on the other, in a way that does not downplay either the role of action or that of structure.

\section{Dominant Theoretical Perspectives on Industry and Industry Change}

Industry matters in numerous theories of organizations. However, there are two theoretical perspectives which put more emphasis than others on the structural properties of industries and their relevance for strategizing and organizing: sociological neo-institutionalism and industrial organization theory. Both perspectives contribute significantly towards gaining a better understanding of strategizing and organizing, and of industries and industrial change, nevertheless, as will be shown below, they fail to capture the multiple facets and dynamics of this process.

\section{Industries as Market Structures: The Industrial Organization Theory Perspective}

The industrial organization (IO) literature defines industry as 'a group of firms producing products that are close substitutes for each other' (Porter 1980: 5) and frames it mainly in terms of product differentiation, customer and supplier concentration, size of entry and exit barriers. These industry 'structures' provide firms with some space for strategic manoeuvring, while their own structures follow more or less logically from these strategies. Within the classic 'structure-conduct-performance' paradigm, this space was conceived as being largely negligible, yet Porter (1980) and his followers reminded IO theorists that firms still have significant scope at their disposal regarding strategic choice. 
Recent IO theorizing not only pays increased attention to firms' strategies, but has also started to conceptualize how industry structures influence firms' strategies, structures, and performance and how these structures are influenced by them (cf. Minderlein 1993, for an overview). Thus, IO theory has started to model industrial change as an endogenous process. Nevertheless, it continues to conceptualize industry in fairly static terms, not least because it neglects the growing importance of cooperative strategies (with the exception of collusive behaviour) and network forms of organizations (see, however, Harrigan 1985, for an early and notable exception). Furthermore, IO theory has not yet developed a satisfactory understanding of how processes of situated interactions are shaped by industry structures and how these interactions, in turn, produce and reproduce these structures.

The relative disregard of general change within an industry, and particularly of the change towards and via interorganizational interaction and cooperation, comes as no surprise, since IO is not conceptually well-equipped to contribute to our understanding of the processes of change within an industry, neither to the (path-dependent) evolution of industry, nor to the social significance of general relations between economic agents and of interorganizational relations in particular. Moreover, and despite conceptual extensions and elaborations (mainly by integrating ideas from transaction cost and game theory), this theory still overlooks the importance of cognitive and normative industry structures, which other approaches have conceptualized as 'cognitive communities' (Porac et al. 1989), 'institutional logics' (Thornton and Ocasio 1999), 'industry recipes' (Spender 1989) and 'industry mindsets' (Phillips 1994). IO theory is thus incapable of conceptualizing the recursive co-evolution of these industry structures and organizational forms. Nevertheless, with its focus on the resource structure of markets and their impact upon efficiency, it provides us with obviously relevant, even if partial, analytical categories. In order to grasp their importance for processes of industry constitution, however, a more processual or evolutionary theory is needed.

\section{Industries as Organizational Fields: The Sociological Neoinstitutionalism Perspective}

The new institutionalism in organization theory, not surprisingly, stresses the importance of organizations and, of course, institutions. Moreover, it conceives industries as 'organizational fields'. Following DiMaggio and Powell (1983: 143) this notion refers to

'those organizations that, in the aggregate, constitute a recognized area of institutional life: key suppliers, resource and product consumers, regulatory agencies, and other organizations that produce similar services or products.'

The concept of the organizational field adds to the SIC population, formally classified by the IO approach to industry, 
'those other and different organizations that critically influence their performance: e.g. suppliers, customers and regulators. [...] [Thereby] organizations are in the same field if they take one another into account, regardless of geographical propinquity.' (Scott 1994: 206)

Organizational fields are sometimes operationalized in terms of four levels: constellations of actors, technologies used, regulations established (by state agencies), and practices characterizing the activities in the field (Leblebici et al. 1991). The survival of organizations in a field is assumed to be determined by the extent to which these are capable of adhering to institutional structures, or rules, of an industry and, thereby, of gaining legitimacy. Organizational efficiency, at least from the perspective of neoinstitutionalist theorists, is only one, and often not even the most effective, way of gaining legitimacy in a field.

The concept of the organizational field refers to linkages among relatively autonomous organizations as well as to relations of ownership, authority, and power (Scott and Meyer 1991). Because of its focus not only on competitive but also on cooperative exchange relations, cooperative strategies and network forms of organizations have been a genuine object of neoinstitutionalist research for quite a while (cf. Powell et al. 1996, for a prominent example). Nevertheless, these forms of organization, from an institutional perspective at least, reflect rather than influence the cognitive and normative structures of an industry.

As DiMaggio (1986: 337) asserts: '[T]he organizational field has emerged as a critical unit bridging the organizational and societal levels in the study of social and community change.' The basic neoinstitutional assumption that the interplay of the organizational and societal level is influenced mainly by wider belief systems and bundles of rules is certainly one of the strengths of this theory, because it systematically adds a cognitive and/or normative dimension to analyses of industries. However, it thereby downplays the importance of resources and power, in particular, when analyzing change within an industry (Brint and Karabel 1991; Orru et al. 1991; Thornton and Ocasio 1999). Other shortcomings of this theory are related to its neglect of change (Hirsch 1997) and the myriad ways in which 'organizations can shape the institutional environment in which they operate' (Powell 1991: 201).

Overall, a perspective which takes the idea of co-evolution seriously should overcome the narrow and rather static understanding of industry promoted by IO theorists, who, if at all, conceive organizations as contributing to the development and reproduction of an industry in a way which largely focuses upon resource structures and efficiency outcomes. In addition, it should consider the institutional factors relevant to the reproduction of industry, such as belief systems and rules of legitimization, broaden the scope of relevant actors and open up to the multi-level and multi-causal constitution of industry. All these aspects are rightly emphasized by neoinstitutional theory. Thus, a truly co-evolutionary perspective should consider the relevance of rules and resources, but also the quite active role of reflexive agents in the social interaction in which these rules and resources, on the 
different levels, are (re-) produced. While IO theory seems to supplement the neoinstitutionalist theory nicely, with respect to relevant aspects of industry constitution, they both lack an elaborate understanding of the production and reproduction processes by which these structures are brought into life, established and changed.

\section{Towards a Co-evolutionary Perspective on Industry and Change within an Industry}

It comes as no surprise that other perspectives have been proposed to capture the essence of co-evolution, that is, the interrelated development of organizations and their competitive and institutional environments (e.g. Aldrich and Mueller 1982; McKelvey 1997; Lewin and Koza 1998; Madhavan et al. 1998; Anderson 1999; Boisot and Child 1999; Miner and Anderson 1999). Such perspectives are particularly needed in studying networks, which are assumed to be more intertwined with their environment than are single organizations.

\section{Industries as Recursively Constituted Social Systems: The Structuration Theory Perspective}

Structuration theory, as laid out by Giddens $(1976,1979,1984)$, is but one promising candidate, since it focuses on just this contingent process of social constitution. By taking up central aspects and arguments of IO and new institutionalism, a perspective based upon the theory of structuration may overcome the limitations of these approaches and provide us with a sophisticated basis for a theoretically elaborated co-evolutionary approach.

Analyzing the constitution of industries from a structurationist perspective means, at first sight, something similar to what DiMaggio, Powell and others in the neoinstitutional framework assume: taking a look at social practices by and through which industries are constituted (Windeler 2001). In contrast to authors in that research tradition, however, a structuration perspective highlights the importance of reflexive agents and their actions. More precisely, it points to the recursive interplay of social interactions and social systems (such as organizations, networks, and industries), which is

'grounded in the knowledgeable activities of situated actors who draw upon rules and resources in the diversity of action contexts.' (Giddens 1984: 25)

That is to say, agents reflexively refer in their interactions to rules of signification and legitimation as well as to resources of domination. Structuration theory, however, emphasizes that the sets of rules and resources, i.e. structures, are always specifically related to the social system within which agents act.

Even on an industry or societal level, institutions are not considered to be 
disconnected from the activities of knowledgeable agents. On the contrary, agents selectively actualize them in their interactions and continually reproduce (or, perhaps, transform) them in and through situated interactions. Thus, industries and their structural properties, such as the degree of product differentiation, the status and power of producers, key customers and suppliers, or the level of industry trust are recursively 'created' by individual and corporate agents who knowledgeably generate products and practices in their contextually situated interactions.

Knowledgeable agents are thereby not only - as neoinstitutionalists maintain - oriented by wider belief systems and bundles of rules of legitimation. By contrast, and in the 'economic sphere' (Giddens) in particular, their actions are predominantly guided by allocative resources, i.e. practices of resource utilization in order to create and market products and services. Only the usage of these resources, oriented by the prevailing rules of signification and legitimation, enables firms to augment these very resources, not least their disposable capital, and to satisfy shareholders' interests. Unlike IO theory and neoinstitutionalism, structuration theory does not assume ex ante that firms or networks of firms strive for efficiency or legitimacy. Rather, performance measures of organizational and interorganizational activity are analyzed in the light of prevailing rules of signification and legitimation, on the one hand, and their interplay with allocative and authoritative resources, on the other (cf. Sydow and Windeler 1998).

\section{The Co-evolution of Organizational Form and Industry as a Structuration Process}

Strategically placed actors which, like state agencies, powerful firms, and industry associations, occupy a certain position in an industry (Podolny 1993) and intentionally influence the structures of that industry. For that purpose, actors critically evaluate data that represent the industry in which they are active, but, as with all action, they act on the basis of partly unacknowledged conditions, and their action has not only intended, but also unintended consequences. Thus even strategically placed actors are never in a position to fully control the constitution processes.

Analyzing the co-evolution of organizational form and industry as a structuration process means understanding how industry and (inter-) organizational practices are constituted by knowledgeable agents. Industry practices may thereby be regarded as those practices which members of a particular industry view and handle as characteristic of that industry. (Inter-) Organizational practices, by contrast, may be defined as practices which agents typically use for coordinating activities and relations in (inter-) organizational systems such as firms, markets, or inter-firm networks. In the latter case, these processes can be called network practices, if individual or corporate agents (e.g. firms) dominantly coordinate their activities by referring to enduring sets of interrelationships between network agents in time and space (Windeler 2001). Investigating the constitution of these practices implies a rather different approach to that preferred by IO and some neoin- 
stitutionalists. Agents do not act in firms, markets, or networks conceived as externally given. Rather, knowledgeable agents interact with other actors and, thereby, actualize practices and structures of the respective social system.

Practices, as a series of 'practical activities' (Giddens) ongoing on either the industry, the network or the organizational level, are not identical, not even in the face of increasingly blurring boundaries of industries and of organizations. Network practices of new players, for example, may contradict established industry practices, and many practices used industrywide may be used in a very different manner to coordinate a particular (inter-) organizational system in that industry. Moreover, agents may rely more on (inter-) organizational rather than industry rules, as Ocasio (1999) found in the case of founder-led firms that lack experience with succession, or the other way round. This shows that industry and (inter-) organizational practices, as will be argued in more detail shortly, are related to each other. Agents refer to both in their acting and, thereby, actively constitute this relatedness.

From a structuration perspective, organizational forms (such as markets, firms, networks) and industries (such as the TV industry) co-evolve (see Figure 1). In this process of recursive constitution, industry practices based upon rules of signification and legitimization, as well as upon allocative and authoritative resources characterizing this particular industry are actualized in interaction and thus influence the social practices within a particular organizational form $(\downarrow)$. The kind of actualization of industry structures in network practices for instance, in turn, influences the evolution of practices within the industry $(\uparrow)$. Production practices in interfirm networks, for example, may reflect a changed level of competitive intensity, due either to a rearrangement of strategic groups or to the market entrance of new competitors. Since network agents are likely to realize the changed situation within the industry they will most probably align their network practices to the changed context. For instance, in times of broadcasters' increasing concern about the cost of programming, producers put more emphasis on cost-cutting outsourcing practices. This, in turn, has an impact on industry structures and practices, especially if the network of agents is quite powerful. In effect, the network may thus contribute to stabilizing the competitive intensity on a higher level in this particular industry.

Nowadays, firms increasingly try to augment their resources by engaging in network activities. While these (network) organizations thereby make use of industry rules and resources, they do not control all effects of their usages, neither on the level of the organization, nor on that of the network or the industry. Nevertheless, they quite often actively participate in creating and/or shaping institutions within industry, such as business practices, educational institutions or regulatory agencies, and thus the terrain in which they act. Because of these more or less strategic activities and the (at least partly) uncontrolled and unintended consequences of their own actions and those of others, the context (or the 'landscape' from a complexity theory 
Figure 1

Processes of Recursive Constitution: A Structurationist Model

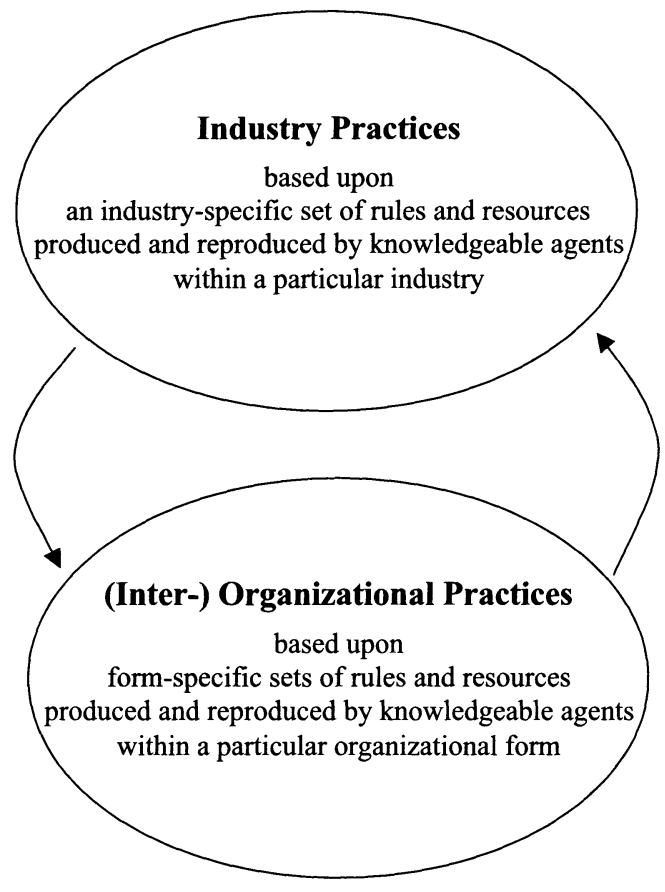

point of view) in and on which agents act continually shifts. However, agents not only adapt to external constraints, but actively and reflexively use them to further their own interests, and eventually change them. The options that agents consider are therefore constituted, but never determined by, the interplay of firm and network actions and the landscapes in which they are active.

\section{The German TV Industry: Structural Properties in Change}

The German TV business, topped in volume only by the US market, is, at least in two respects, truly European. First, public broadcasting is and continues to be very important. Second, the German TV business is highly regulated by government and public agencies, not only with regard to public, but also to private TV, which entered the market only some 15 years ago. The importance of these two structural properties would be illuminated by both IO theory as well as neoinstitutionalism. However, only a structuration analysis explicitly considers that such properties are a medium and outcome of action.

Although public broadcasting stations continue to be two of the four most significant players in the market, the birth and growth of private stations have transformed the German TV business into a dual system. The introduction of this system can well be considered as a disruptive event, more 
precisely a 'structure-loosening event' (Madhavan et al. 1998), which radically changed the basis for competition and significantly affected the structure of interorganizational relationships in this industry, including the power positions of central and peripheral firms. This endogenous shock, caused by established players in the field struggling to establish or inhibit private television for nearly 20 years, resulted in government de-regulation of the established order, and the respective change of legal institutions, as stages in a new regulation offered many 'occasions for structuring' (Barley 1986). In what follows, we will describe the emergence of the dual system which, at least on the surface, affected first and foremost the structures of TV distribution. However, a deeper analysis of this structural change, which was triggered by de-regulation and privatization, shows that a significantly different form of production organization co-evolved: collaborative content production in project networks.

\section{The Evolution of the Dual System: Public and Private Broadcasting}

Because of the misuse of a centralized state-owned broadcasting system during the Nazi era, the Allies forced the German state parliaments to introduce a highly decentralized and truly public broadcasting system, modelled on the BBC and based on licence fees in order to keep it quite independent from both central state power and market influence. German TV consequently developed into a public duopoly made up of the ARD (or more precisely, the ten regional stations within this Germany-wide public partnership) and the ZDF, which was founded some years later. For years to come, television in Germany was considered as duopolistic, non-commercial, and emphasizing information rather than entertainment. In the face of a lack of viable alternatives, public television was well accepted by the audience and, despite repeatedly criticized resource-inefficiencies, was seen as a legitimate institution.

This structure of the industry did not change until the mid 1980s when, due to deregulation and liberalization and the influence of media conglomerates (like Bertelsmann and Kirch), private broadcasting stations were approved. In a rather different way than assumed by IO theorists and neoinstitutionalists, new structural and institutional features of the TV industry have emerged, among them a high degree of economic concentration, sizeable entry and exit barriers, accustomed yet changing viewing habits, and enduring legal regulation. These new features are being produced and used by mighty agents such as the four major broadcasters. Another structural property to which agents repeatedly refer concerns programme financing. While the prime stations of the Bertelsmann and Kirch groups, i.e. RTL and SAT.1, respectively, finance their programming via advertising, and are thus forced to go for high 'quotas', the public stations continue to be mainly financed by licence fees paid by everybody who owns a television set (currently more than Euro 15.00 per month). Since the latter stations still raise only about 10 percent of their budgets via advertising (which is allowed for only 20 minutes on weekdays before $20.00 \mathrm{hrs}$ ), they can 
aim their programming at criteria other than just quotas, although this quantitative measure has recently gained a lot of relevance for legitimizing the activities of public stations as well.

Since the mid-1980s, the Kirch Group (with not only SAT.1 but also Pro 7, DSF and, as a pay TV platform, Premiere World) and Bertelsmann (with not only RTL but also RTL2, Super RTL, and Vox) have, despite extraordinary costs, set up additional full programmes. Furthermore, the regional stations within the ARD have started to broadcast complete and fully competitive programmes via satellite and cable. In addition, broadcasters from other European countries (BBC, TV 5) and the United States (MTV, NBC, $\mathrm{CNN}$ ), as well as German special-interest channels (ntv, Viva - both of them partly supported financially by foreign firms) have entered the TV business via satellite or cable. As a result, German viewers can now receive more than 30 channels, either via satellite or, at least in the metropolitan areas, via cable. Thus, with regard to the structure of competition, the industry has been transformed in a fundamental way.

Despite this significantly increased level of competition, the two largest stations of each group, the public (ARD, ZDF) and the private (SAT.1, RTL), together still have a market share of circa 70 percent. As strategically placed actors, these four broadcasters, shape the development of the TV business in Germany more than others, and, despite persistent government influence, the vibrant rules and resources of this industry. For instance, these key players have contributed significantly to the fact that, in the same way as being under the aegis of public broadcasters, significant resources are spent on high quality programming adapted to the needs of a relatively fastidious German speaking audience. Therefore, this high quality programming, despite considerable changes in some other respects, continues to be a structural property of the industry. Many resources are legitimately used to produce this type of programme.

This is not only true in the area of entertainment, but also as far as informational content (e.g. news, documentary) is concerned, although the public stations have been able to sustain a competitive advantage in terms of credibility in this latter category of programming (Tebert 2000). However, public TV stations now spend more resources on sports and entertainment in order to stabilize their market share, a strategy which in the long run, may undermine their capability to sustain this competitive advantage. In fact, the legitimacy of this strategy is questioned by some politicians and, above all, by private broadcasters, who argue that broadcasting these contents is beyond the commissioned task of public TV. This shows, by the way, that simply adopting isomorphic practices may not increase the legitimacy of an organization or institution in an industry. Rather it seems to be important for broadcasters - as well as for producers and production firms - to adopt organizational and, eventually, interorganizational strategies that 'fit' the relevant set of rules and resources of the particular industry at a particular moment of time. Though, most of the time, these structures have been highly contested and agents have tried to remain sensitive towards future changes, adopting these strategies will almost cer- 
tainly contribute to the powerfully brought about reproduction of these industry structures.

\section{The Organization of Content Production: Convergence Between Public and Private Worlds?}

With the disruptive event of the birth and growth of private broadcasting in Germany, not only the programming has changed but also the organization of programme production (or, in more general terms and content, in the face of DVB and the Internet). Until the mid-1980s, the public broadcasters ARD and ZDF were rather vertically integrated firms characterized by a high proportion of in-house production. RTL, in particular, but also SAT.1, both of them founded around that time, followed a very different model. They sourced content from outside the firm. At the time of their founding, they bought up many TV series available on the, mainly US, market. Faced with increasing prices and diminishing quotas for this kind of programming, SAT.1 and RTL opted for organizing content production in networks ('contract production'), not least because these private broadcasters did not have the necessary in-house facilities. Moreover, these facilities were considered more costly and less innovative, and therefore not at all fitting for an increasingly volatile environment.

Contract production in networks also became a viable alternative because of the emergence of a significant number of independent production firms. This was an unintended outcome of the - in the meantime well-established - strategy of the public stations (especially the ZDF) to farm out at least some part of their content production. In addition, the global discussion about suitable ('lean') models of production organization and the transformation of the Hollywood studio system into more flexible modes of production provided an institutional context which made these new organizational forms - as a kind of 'mimetic isomorphism' (DiMaggio and Powell 1983) - appear not only legitimate, but necessary. While disaggregated modes of (film) production did not necessarily prove to be (as in the case of Warner) a cost-cutting measure, 'it helped the studio system to adapt its output to meet changing patterns of market demand' (Robins 1993: 115). The same seems true for the production of TV content in networks.

Soon, RTL used these sets of rules and resources to set up a decentralized production network in the Cologne area. The fact that, at that time, RTL only required a staff of 600 for producing and broadcasting a complete TV programme, while the WDR (the largest regional station within the ARD, also situated in Cologne) required 3,000, can only be explained by this very different organization of production. Nevertheless, this different mode of production organization in the private world, together with fast-increasing programming costs, caused by an increase in demand for original, innovative and distinguished content, has stimulated public broadcasters to farm out production either to equity-owned production firms or to networks of independent producers. While there is (still) wide variety in the amount of 
production outsourced, even within public broadcasting, ${ }^{3}$ the public world seems to be converging with the private world to some extent, not only in programming and distribution, but more especially in the organization of content production. ${ }^{4}$ These corporate agents, via their programming, distribution and production strategies, seem to refer to rules and resources which are less different between these two worlds than they used to be. For instance, public broadcasters have learnt from private broadcasters the art of programme scheduling to retain viewers' attention once they have switched to a particular station. They have also learnt to source content that fits and develops the station's strategic profile (Windeler et al. 2000).

As a result of this strategy of farming out content production, the number and size of TV production firms in Germany has increased significantly. Now there are about 1500, including subsidiaries of US media groups (e.g. Columbia TriStar, All American Freemantle), and some relatively large independent producers such as Endemol and Ziegler, several firms owned by Bertelsmann (e.g. Grundy UFA), the Kirch Group (e.g. Taurus Film), or even the public broadcasters (e.g. Bavaria, Studio Hamburg), and hundreds of small and very small establishments. Within the last three years, the volume of programmes produced in Germany under the aegis of public and private broadcasters has increased from Euro 1.3 to 1.8 billion, not including the fast-growing business of developing TV-programme-related content for the Internet, which may soon serve as the basis for DVB via the Internet. ${ }^{5}$ While the German market for TV content, very much in contrast to the market of broadcasters, does not exhibit an oligopolistic structure, tendencies towards such a structure can be identified in those areas which require not only an extraordinary talent but also an extraordinary amount of capital (e.g. the production of soap series)(see Windeler et al. 2000 for details).

Thus, the organization of content production for German TV, which was originally comparable to the studio system, has moved, in the face of the dual system, towards an organization of production in inter-firm networks or, more precisely, towards collaborative content production in project networks. Nevertheless, alternative forms of coordination of content production continue to co-exist under a single institutional (regulatory) arrangement. Before the dual system was established, agents used collaborative practices and market relationships in addition to in-house production. Today, under the dual system, the situation is rather similar, although the dominant organizational form has changed from in-house production to project networks.

While there has been a significant trend towards convergence as far as the form of production organization is concerned, project networks and the content they produce tend to stay focused on either the private or the public world. Until now, the only production firms that produced for both worlds were those that are part of media groups or important independents. However, in order to adapt to the different sets of rules and resources that still existed in the private and the public worlds, they make use of interand intraorganizational differentiations. For instance, Colonia Media, a 
Cologne-based production firm and part of the Bavaria Group (which is jointly owned by two major public broadcasters, BR and WDR), not only creates distinct project networks for the two worlds of production, but also pursues a strategy of internal differentiation.

In turn, the development of network forms of production organization has rather radically shaped the practices of content production within the industry. In the mid-80s, in-house production was signified as the most appropriate form of production; and respective rules of legitimation and resources of domination backed this view. Today, the sets of rules and resources of the industry, despite continuing differences between the private and the public world, have changed and now sustain in-house production as a dominant form of organization in the special sphere of news production. In all other programming areas rather different rules and resources have coevolved with the content production in project networks.

The driving forces behind this trend have been strategically placed agents referring, in their actions, to the general expansion of the TV industry; the diversification of established broadcasting stations and the entrance of new (private) ones; the pressure for innovative and even more cost-efficient and risk-sensitive production methods; the parallel emergence of more or less independent production firms. These actors, either on their own or in networks of organizations, shape industry structures. For example, they source content from commissioned producers or establish new educational institutions (such as schools for authors and game-show convenors). These structures and institutions do not, as IO and neoinstitutionalist theory assume, emerge 'somehow' and then constrain action. Rather, they are the intended or unintended results of the strategic actions of mighty industry players, not only of the two public and two private broadcasters, but also of some major production firms with which they interact. The more recent globalization of television and the trend towards digital TV, which can also be looked at as disruptive events, will hardly reverse the evolution of this network form of collaborative content production but will have the effect more of consolidating it, even if some network members exit and others enter project networks and some network practices are reshaped (cf. Scott 1996). ${ }^{6}$

\section{Collaborative Content Production and the Institutionalization of a New Production Model}

Despite many variations in detail and never ending struggles over forms of production coordination, particularly with regard to the public and private worlds of the German TV industry, project networks have evolved from both global sourcing strategies and from vertically integrated production systems, and they now seem to dominate content production. Moreover, these networks seem to provide the social context in which new orientations and norms governing 'What is a good programme?', 'What constitutes efficient project management?' and 'Which labour standards are 
appropriate?' emerge and are institutionalized. Thus, this form of production organization not only has implications for the allocation of resources within the TV industry, but also for the reproduction of cognitive and normative rules, which are a necessary and important component of an advanced understanding of industry and industry change.

\section{Project Networks - The Dominant Form of Content Production in the German TV Industry}

Project networks are conceived as a means of coordinating activities among relatively independent firms (including artists and artisans) for carrying out a temporary task whereby the network firms coordinate their project activities by referring to established sets of relations and practices beyond (sic!) the ongoing project. Hence, project networks are 'temporary systems' (Goodman 1981) insofar as the project activities are temporarily limited; however, they are more than just temporary systems, because every new project is based upon the experiences of collaboration in earlier ventures and are carried out in face of the 'shadow of the future' (Axelrod 1984). In fact, empirical studies of project work in construction (Stinchcombe 1959; Eccles 1981), software (Sieber 1998), feature film (Faulkner and Anderson 1987; Robins 1993; Jones and DeFillippi 1996; Blair 2001), and, last but not least, TV programmes (Tempest et al. 1997; Mast 1999; Nachum and Keeble 1999) document the fact that the relations between project members survive the single project. In many cases, they last for years. Such rather stable relationships have a significant impact on the formation and coordination of project networks. They enable independent firms to come together for a relatively short period of time, in the case of content production for TV often for as little as a couple of weeks, and nevertheless to coordinate their activities quite effectively.

A provider of a programming idea, usually the author, or a broadcaster commissioning the production of a certain programme, stimulates a producer to form a project. In most cases, this will include one or, as in the case of series and soaps, several authors, a director, a cameraman/woman, talent agencies and several other providers of creative and technical media services (see Figure 2). ${ }^{7}$ Often, these actors enter the project as fixed pairs (an author-director dyad, for example; see also Faulkner and Anderson 1987) or constellations, a kind of 'semi-permanent work group' (Blair 2001). Despite the coordinator role of the producer, at least some of the network firms not only sustain indirect but also direct relations (e.g. the director and his relations with providers of creative and technical media services).

However, while it is quite clear that interpersonal and interorganizational relationships influence the possibilities and limitations regarding the coordination of these temporary systems, the constitutive mechanism which turns projects into a network form of organization and, hence, makes their coordination not only feasible, but also efficient, has not been elaborated until now. 
Figure 2

Project Network

as an

Organizational

Form

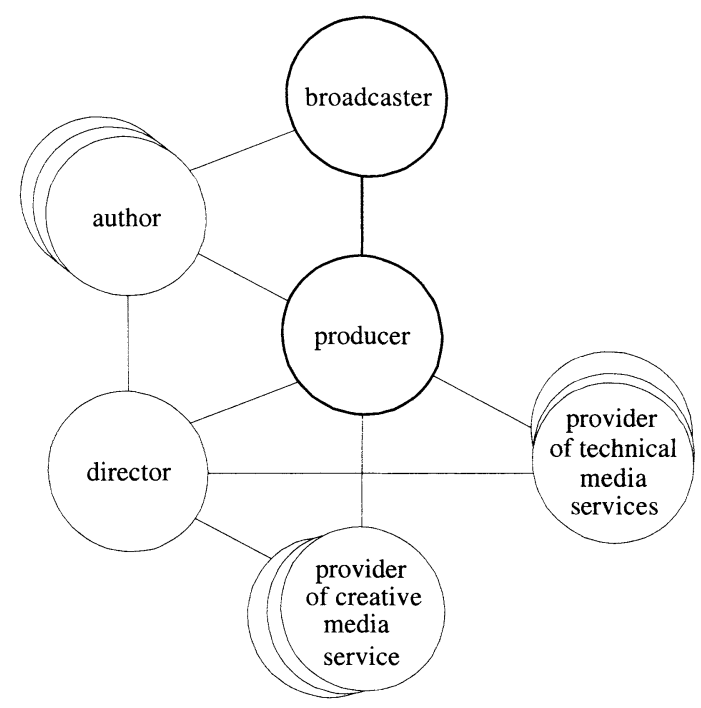

Network practices emerge from recurrent collaboration in several projects, be it the production of a TV feature, a 13-part series, a weekly or daily soap, or a short contribution to a magazine. The producer, usually in close collaboration with the broadcaster, (re-) selects the members and coordinates the activities of the project by referring to network rules and resources. For instance, the project members, due to long-term experience of collaborating in similar projects, share a deep understanding of how important it is to deliver a TV movie in time and of the agreed quality that fits the strategic profile of the station. To give another example, the members of the project network are used to the (network) practice that a supplier of a particular artistic or technical service has to have a minimum reputation before being selected as a project member. While every project is unique, to some extent at least, the producer, and all the other project members too, rely heavily on experiences with, and future expectations of, such network practices. Each practice considered successful is likely to be reproduced and it strengthens the affiliation with the pool of individual and corporate actors from which the actual project members are recruited. This mechanism, which is typical of project networks, supports the coordination of project activities, reduces transaction costs and enhances the adaptive and creative capacity of this organizational form. However, the institutional embeddedness of project networks in industry structures is of major importance for the functioning of this mechanism, since network structures and practices, although necessary, are usually not sufficient for achieving coordinative efficiency. Moreover, if project networks lack regulations, network agents substitute them by adopting sets of rules and resources established on the industry level. 


\section{The Embeddedness of Project Networks in the TV Industry}

Project networks constitute themselves in industries, and are thus influenced by industry structures, i.e. sets of industry rules and resources, but, at the same time, they shape these very structures. In the case under consideration, this means that, in their ongoing projects, actors actualize practices, activities and relationships which are common to the German TV industry and shape these very practices by their actions.

Industry-wide recipes for organizing the inter-firm division of work efficiently, to elaborate a first example from the list in Figure $3(\rightarrow)$, are sedimented in a common language about, for example, sequences of the production process, tasks to be carried out before the shooting of a film takes place, people to be hired for post-production, and 'rights' granted to authors and programme editors to influence co-opting into the project a particular director or service provider. Such recipes are also manifest as rules of legitimation concerning, for example, the necessity of the activities themselves and as domination resources needed for carrying out these activities.

Labour standards are just another example. It is true that important characteristics of the German system of industrial relations (relatively high unionization, collective agreements, works councils, etc.) can hardly be found in the media industry. Nevertheless, labour standards have emerged and are usually reproduced by network agents without much variance. These industry-wide standards regulate, though on a rather informal basis, for instance, the earnings and working hours of particular groups of employees (such as cameramen/women, authors, and visagists). They also suggest which kind of job should follow in the unrestricted career which is typical of this industry (Jones and DeFillippi 1996). The members of the project network, most of all the producer, refer to these rules and resources in order to coordinate differentiated network practices and to secure interactions in a network-based production process which is typically characterized by highly-specialized work roles and severe budget constraints. By doing so, in the project network, s/he reproduces or transforms these rules and resources as industry structures in a co-evolving process, still to be explained.

Network practices make the realization of a project more likely, because they meet the expectations of the commissioning broadcaster. The expectations and actions of network members are based on industry-wide sets of rules and resources. Although these practices also contribute to the rule sets and resources of different social systems, the TV industry and the project network included, the structures of these systems, including the recipes and standards, are not necessarily compatible. Where they are in conflict with each other, they provide (additional) occasions for institutional change and network-specific adaptations. ${ }^{8}$ 
Figure 3

The Recursive Interplay between Industry and Network Practices Examples from the German TV Industry

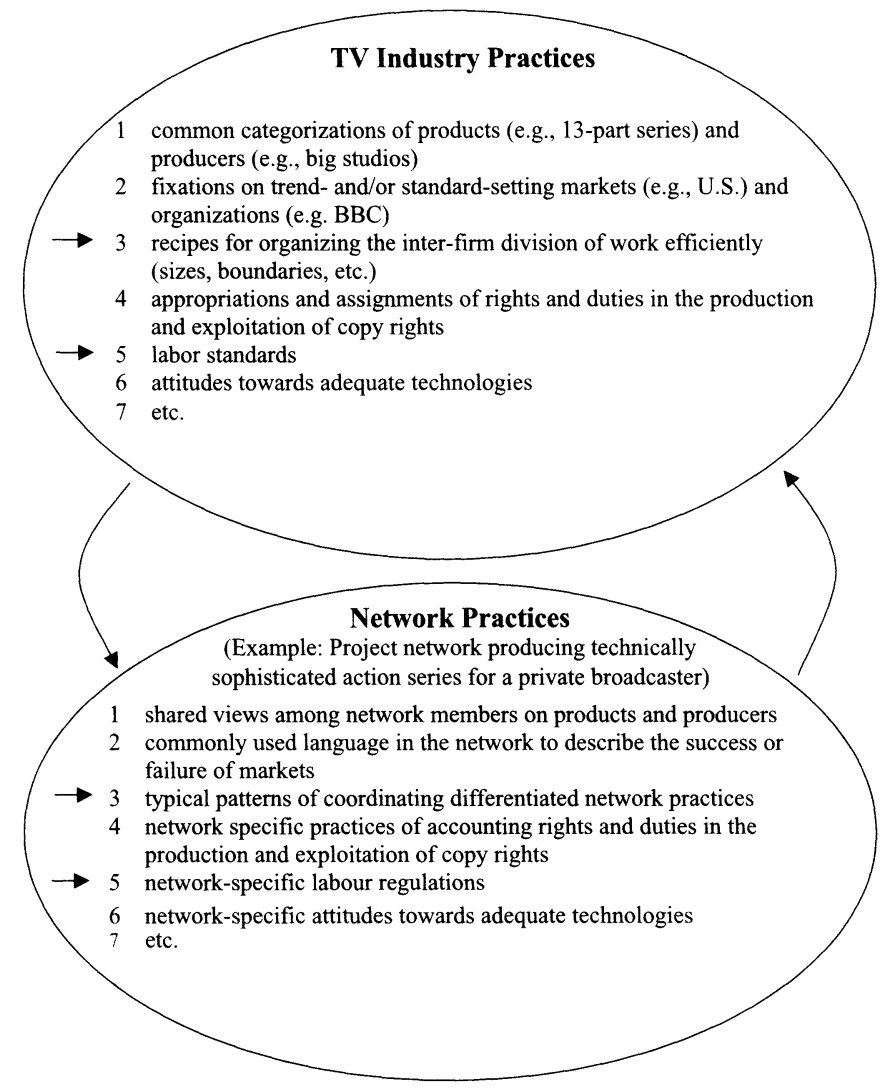

\section{Idiosyncrasies in Project Networks and How They Relate to Industry Structures and Change}

It is true that the interpretative schemes, norms and facilities that agents use in interaction are idiosyncratic and situation-specific. However, agents constitute the schemes, norms and facilities that they use in situ by applying those rule sets of signification and legitimation and domination resources that characterize the different levels of the system. For instance, in their interactions with other participants of the project network, producers often actualize the expectations of powerful representatives of broadcasters, such as programme editors, concerning industry-wide quality standards and adherence to budgets, both of which are shaped by powerful agents. The producers, by introducing their own ideas to them and convincing them that the final product will fit into the broadcaster's profile, in turn, influence those people who span the boundaries of broadcasting organizations. In the end, 'mutual knowledge' (Giddens) develops between editors and producers, making coordination of their activities in the project network not only possible but - hopefully - efficient and thus legitimate. 
What is true for the relationship between programme editors and producers also applies, at least in principle, to those between the producer and the authors, directors, and providers of artistic and technical media services as well as to those between authors and directors, cutters and directors, and so forth. All these relationships incorporate, and are based upon, shared norms, common understandings, and experiences with coordinated practices, not only on the level of the network, but also on that of the industry. These structures inform each interaction, for instance, the negotiation and re-negotiation of contracts, the selection of project partners, the communication of quality standards which have to be met by the final product, and so forth. Against this background, producers know with which partners they are able to develop the product to the level of quality expected by the broadcaster and to keep the project within the time and budget frame agreed with the patron. This is crucial because there are usually no slack resources to allow common understandings, shared norms, etc. to develop. This is why it is so difficult for other firms to enter a well-functioning network, unless of course, they are needed because of their specific competence (e.g. special-effect agencies).

When new firms enter an established project network, or even the industry, they are likely to bring new perspectives, norms, and practices with them. ${ }^{9}$ They do not, however, simply substitute common network and industry practices, but are likely to amalgamate old and new ones. The adoption of US programmes by private broadcasters, to give just one example, was successful in Germany for around five years (1985-1990). Today, formats of US series are used, but the content and sometimes even the format is adapted to German culture and, consequently, produced locally in the production networks in and around Cologne, Berlin, or Munich. Original content from the United States only finds its way into German TV outside prime time viewing.

\section{The Institutionalization of New Practices in the German TV Industry}

After the dual system had been established, the foundations were laid for new industry practices to gain legitimacy. Since the change towards this system can and has been analyzed in terms of privatization, also by powerful agents of the field, calculating and control practices which aimed at greater efficiency were put into practice, not only by private but also by public broadcasters. Shortly afterwards, this was followed by the larger production firms which, at least in some cases, are part of media conglomerates and thus familiar with such practices. Local efficiency gains, realized in particular project networks, were soon generalized and used to shape the industry rules of signification and legitimation and the dominant form of resource usage underlying recipes for organizing content production in this industry. One of the more famous examples in this respect is the talk within the industry about the private broadcaster RTL being able to produce a complete programme with a staff of only 600 , while the WDR employed 3000. Though this talk was questioned by insiders, who pointed to the 
opaque employment effects of the then new form of collaborative content production in project networks, it was readily accepted as possible by those parts of the TV industry (private broadcasters and producers) as well as by those politicians and scientists who were in favour of further privatization of the German TV industry. In the struggle to find more appropriate means of measuring efficiency and effectiveness of programming and production of content which accompanied the privatization process, the public broadcasters and politicians in favour of public broadcasting were defeated. Quality standards adopted by public broadcasters as dominant indicators for legitimate programming were consequently replaced by quotas, the main measure of success for the private stations.

There are at least four mechanisms that contribute to the spread of new practices and their institutionalization on an industry level.

1. The project network itself plays a central role in this process, via its coordination mechanism which reaches beyond the single project. The practices developed in one project soon infect the whole pool of agents usually involved in the production of a specific content.

2. The interactions between programme editors and producers are obviously not mutually exclusive. Both are involved in different projects and are most likely integrated into different project networks, possibly even at the same time. If this is the case, their interactions contribute to the diffusion of network practices in the industry.

3. Network agents reflect on the contextual appropriateness of certain production practices and, thereby, eventually produce new industry recipes which are likely to be applied by other actors in the field for the very reasons outlined above. This is particularly likely if they are, at least for the time being, considered to be 'best practices'.

4. A group of agents involved in collaborative content production, especially one that is reflexive towards what 'is new' and what 'works' in the industry. If it is also engaged in building and running organizational institutions which support the industry (e.g. educational programmes, standardization committees), it thereby furthers the institutionalization of new industry practices.

Dense networks of relationships between important agents in the field, like the ones between broadcasters and production firms, might enhance the speed and expansion of the above practices. However, they may also, depending upon the concrete network structures, impede their spread. Innovative practices, for instance, may not be adopted since established agents in the field are repeatedly selected for collaborative production of a specific content.

\section{Industry Constitution and Change as a Recursive Process: Conclusions}

The research question posed in the introduction of this paper concerned the rise of the network form of governance in the Germany TV industry from, on the one hand, conventional forms of in-house production (popular with public broadcasters at that time) and sourcing content from overseas mar- 
kets (popular with early private TV), on the other, and how this development is related to changing industry structures and practices. The paper argued that, very much in line with the disaggregation of the Hollywood studio system, public and private broadcasters in Germany moved towards the model of collaborative content production in project networks in order to secure the delivery of a type of programme that was original, innovative, culturally adapted and yet cost-effective. The main focus of inquiry, which was undertaken from a structuration perspective, concentrated on the question 'How did the organizational form interrelate with the industry context in the evolutionary process of industry change?'

The analysis showed that the evolution and, finally, institutionalization of industry practices does not mean the forced adaptation of externally given practices. The institutionalization is seen more as a multi-level, multidimensional and multi-actor endogenous development, one in which different knowledgeable agents recursively and powerfully refer to industry practices and their underlying sets of rules and resources in their network practices. In so doing, they reproduce or change industry structures on the three institutional dimensions of signification, domination, and legitimation. The development of industry and network processes should thus be understood not only as a co-evolutionary process, but as a co-evolutionary multi-level constitution process.

The analysis of the current mode of production organization in the German TV industry also leads to some general conclusions which could advance the theoretical and empirical analysis of the constitution of industries.

1. Investigation of how knowledgeable agents use the structural properties of an industry (highlighted, for example, by the IO literature), and the common understandings and shared norms (emphasized by neoinstitutionalists), drives theorizing towards a more integrative conceptualization of industry constitution and change. It becomes noticeable how the sets of rules and resources which are characteristic of a particular industry are constituted in interaction by agents who refer to specific rules of signification and legitimation that, for the time being, constitute, for instance, the 'best practice' of content production. In addition, these agents necessarily refer to specific domination resources to enable them to implement, as best practice, collaborative forms of content production in project networks. Thus, a co-evolutionary approach, based upon structuration theory, focuses attention on strategically placed agents (such as major broadcasters and production firms), on why and how they establish a particular form of production organization, and, thereby, on how they affect the prevailing sets of rules within an industry concerning the actual and ideal appearance of modern and efficient production. Moreover, such an approach emphasizes the contingencies of the process, and the fragmented conjunctions, slow drifts and opportunities that agents are likely to use strategically. In contrast to the more or less static perspectives on industry and industry change based upon IO and neoinstitutional theories, such an approach focuses on social practices - the process by which these are brought about 
and how they contribute to the reproduction and, possibly, the transformation of industries.

2. In addition, a structurationist view on such co-evolutionary processes emphasizes that knowledgeable and powerful agents, via their activities, constitute practices on both system levels. Nevertheless, and despite a fairly high level of reflexivity, actions in general and those aiming at the organization of a social system such as a project network, network practice or industry practice are only, in part, intentionally and strategically shaped; in other parts, they are an unintended consequence of otherwise intentional action. A good case in point was the practice of public broadcasters, long before the privatization of that business, to farm out parts of their content production. They thereby prepared the way for independent producers which allowed, many years later, private stations to contest public broadcasters by producing content in project networks. Unintended consequences led to many network and even more industry practices being produced and reproduced without reflexive control. Therefore, the reproduction and transformation of industry structures always have to be analyzed as a melange of reflexively and non-reflexively regulated processes.

3 . Looking at the co-evolution of industry structures and (inter-) organizational practices necessarily implies investigating how industry practices shape network practices, and vice versa. For that reason alone, industry change can take many routes from slow 'drifts', whereby conventions become subtly modified by the ways to which they are 'adhered', to disruptive events. As the case of the German TV industry indicates, disruptive transformations, such as the change from a public broadcasting system into a dual system, not only stipulate dramatic changes in the content production. The processes triggered by this change induce further changes. New production firms (and other agents participating in the production or in financing the production) did not simply adopt the existing forms of production organization, they also imported and still import different views, norms, and practices. Thus, new or newly accentuated practices do not simply penetrate and diffuse the industry. The newcomers are themselves forced to take into account structures dominating the field and assimilate them somehow in their own practices. Hence, changes in industry and production processes, do not simply go hand in hand, but are recursively interrelated and embedded in multi-level processes of co-evolutionary changes.

Such a 'new view' on the co-evolution of industry and network practices sheds some different light, not only on the conceptualization of co-evolutionary processes, but also on the possibilities and limits of reflexive network management. In the first place, it highlights the importance of managerial action, knowledge and reflexivity, and yet points to the relevance of somehow 'emerging' patterns as unintended consequences of otherwise intentional action. Secondly, it attracts attention to the recursive interplay not only among the three social dimensions (signification, legitimation, and domination), but also among the two or even more levels of social constitutions: industry and organizational form, and the subtle and 
complex processes by which they are continuously reproduced. ${ }^{10}$ Thirdly, it points to the fact that a reflexive management of project networks means more than organizing activities in a particular project. The activities in an ongoing project have to (and can) be coordinated on the basis of an enduring set of relationships which reach beyond the single project. These network relationships themselves can become an object of reflexive management. Finally, and concerning the co-evolution of industry and network practices, a reflexive network management includes the monitoring and rationalizing of (the development of) industry practices in order to coordinate the project and, however limitedly, to shape the context of the industry itself.

Future studies could and should not only explore the possibilities and limitations of a (more) reflexive network management, but extend their domain to other project-based industries which are dominated by similar organizational forms and whose number, due to changing customer demand and work values, is growing rapidly, and also co-evolving along with the privatization, globalization digitalization of industries, in an increasingly 'project-intensive economy' (Eckstedt et al. 1999).

1. Former versions of this paper were presented at the conference on 'Competing through Alliance Networks: Changing Dynamics of Industry Structure' at the IESE, University of Navarra, Barcelona, Spain, 27-29 June 1999 and at the 17th EGOS Colloquium 'The Odyssey of Organizing', Lyon, France, 5-7 July 2001. We thank Africa Ariño and Carlos GarciaPont for organizing the stimulating conference in Barcelona and Heather Haveman and Woody Powell for their insightful comments during the EGOS Colloquium. Moreover, we thank Anja Lutz and Carsten Wirth for their support in gathering the data, the Deutsche Forschungsgemeinschaft (DFG) for the funding of this project (No. SY 32/2-1), the guest editors of this journal, Arie Lewin and Mitch Koza, two anonymous reviewers and, last but not least, Günther Ortmann for their valuable comments on earlier drafts of this paper.

2. Giddens (1984: 227 passim) is rather critical of conventional evolutionary theories. Speaking of co-evolutionary approaches in this paper, we refer to more modern theories of evolution and specifically concentrate on the basic idea of co-evolution (cf. Kappelhoff 2000). 3. Ranging from the MDR which approximates, in relative terms, to a hollow public organization to the WDR which still emphasizes in-house editing and even production.

4. Since the world of private TV production is fairly diverse, it is somewhat difficult to speak of a unified trend towards convergence in organizational form. While, for instance, SAT.1 has by and large imitated RTL's strategy to organize the production of its programmes within networks of independent firms, the other Kirch station, Pro 7, is said to be at a strategic disadvantage, as it is still sourcing a large proportion of its programmes from abroad.

5. RTL has just begun to produce a 2-minute daily soap, 'broadcast' only via Internet.

6. An example of a minor change is the inclusion of special-effect providers into more and more projects and, thus, into existing project networks.

7. In some cases, especially in the production of soaps, the producer or production firm not only enters network relationships with other firms, but recruits employees for the time of the project. Eventually, other network firms do the same. Thus, in contractual terms, project networks sometimes consist of a mixture of exchange and (temporary) employment contracts. 8. Other potential sources of institutional change are, according to structuration theory: structural contradictions, increased knowledge, and lack of legitimacy (cf. Sydow and Windeler 1998). This understanding of change equals more or less that favoured in the "economics of conventions' (cf. Boyer and Orléan 1992) which differentiate between changes by 'general collapse', 'external invasion', 'translation' and 'collective agreement'.

9. Although established, long-term relationships with authors, directors, etc. are of outstanding importance for organizing a new project, there are at least two ways for new actors to enter a project network. One is that relevant information is derived from the reputation of a potential network partner, another is that respective information is handed over to the 
network organizer (usually the producer) by a trusted intermediary. This can be any member of the network, including the client (i.e. the broadcaster), although, again depending on the nature of the programme, authors and directors are more likely than others to assist the producer in selecting other network partners.

10. In case management or public policy activities aim at the formation of a regional cluster or industrial district, the same theoretical insights could be used in relation to spatial concepts (cf. Sydow and Sober 2002). In this case, likewise two or even three levels of analysis have to be taken into account: network, industry and district.

\section{References}

Aldrich, H.E., and S. Mueller

1982 'The evolution of organizational forms: Technology, coordination, and control' in Research in organizational behavior, Vol. 4. B.M. Staw and L.L. Cummings (eds.), 33-88. Greenwich: JAI Press.

Anderson, P.

1999 'Complexity theory and organization science'. Organization Science 10/3: 216-232.

Axelrod, R.

1984 The evolution of cooperation. New York: Basic Books.

Barley, S.R.

1986 'Technology as an occasion for structuring: Evidence from observations of CT scanners and the social order of radiology departments'. Administrative Science Quarterly 21: 78-108.

Blair, $\mathrm{H}$.

2001 "'You're only as good as your last job": the labour process and labour market in the British film industry'. Work, Employment, and Society 15/1: 149-169.

Boisot, M., and J. Child

1999 'Organizations as adaptive systems in complex environments: The case of China'. Organization Science 10/3: 237-252.

Boyer, R., and A. Orléan

1992 'How do conventions evolve?' Journal of Evolutionary Economics 2: 165-177.

Brint, S., and J. Karabel

1991 'Institutional origins and transformations: The case of American community colleges' in The new institutionalism in organizational analysis. W.W. Powell and P. DiMaggio (eds.), 337-360. Chicago: University of Chicago Press.
DiMaggio, P. J.

1986 'Structural analysis of organizational fields: a blockmodel approach' in Research in organizational behavior, Vol. 8. B.M. Staw and L.L. Cummings (eds.), 355-370. Greenwich, CT: JAI Press.

DiMaggio, P. J., and W. W. Powell

1983 'The iron cage revisited: Institutional isomorphism and collective rationality in organizational fields'. American Sociological Review 48: 147-160.

Eccles, R. G.

1981 'The quasi-firm in the construction industry'. Journal of Economic Behavior and Organization 2: 335-357.

Eckstedt, E., R.A. Lundin, A. Söderholm, and $\mathrm{H}$. Wirdenius

1999 Neo-industrial organising. London: Routledge.

Faulkner, R.R., and A.B. Anderson

1987 'Short-term projects and emergent careers: Evidence from Hollywood'. American Journal of Sociology 92/4: 879-909.

Giddens, A.

1976 New rules of sociological method. London: Hutchinson.

Giddens, A

1979 Central problems in social theory. Action, structure and contradiction in social analysis. Basingstoke: Macmillan.

Giddens, A.

1984 The constitution of society. Outline of the theory of structuration. Cambridge: Polity Press.

Goodman, R.A.

1981 Temporary systems. New York: Praeger. 
Harrigan, K.R.

1985 Strategies for joint ventures. Lexington, MA: Lexington Books.

Hirsch, P.

1997 'Sociology without social structure: Neoinstitutional theory meets brave new world'. American Journal of Sociology 192: 1702-1723.

Hoffmann, A.J.

1999 'Institutional evolution and change: Environmentalism and the U.S. chemical industry'. Academy of Management Journal 42/4: 351-371.

Jones, C., and R. J. DeFillippi

1996 'Back into the future in film: Combining industry and self-knowledge to meet career challenges of the 21 st century'. Academy of Management Executive 10/4: 89-104.

Kappelhoff, P.

2000 'Komplexitätstheorie und Steuerung von Netzwerken' in Steuerung von Netzwerken. J. Sydow and A. Windeler (eds.), 347-390. Wiesbaden: Westdeutscher Verlag.

Leblebici, H., G. R. Salancik, A. Copay, and $T$. King

1991 'Institutional change and the transformation of interorganizational fields: An organizational history of the U.S. radio broadcasting industry'. Administrative Science Quarterly 36: 333-363.

Lewin, A.Y., and M. P. Koza

1998 'The co-evolution of strategic alliances'. Organization Science 9/3: 255-264.

Madhavan, R., B.R. Koka, and J.E. Prescott 1998 'Networks in transition: How industry events (re)shape interfirm relationships'. Strategic Management Journal 19: 439-459.

Mast, C.

1999 Programmpolitik zwischen Markt und Moral. Opladen: Westdeutscher Verlag.

McKelvey, W.

1997 'Quasi-natural organization science'. Organization Science 8/4: 352-380.
Minderlein, $\mathbf{M}$.

1993 'Industrieökonomik und Strategieforschung' in Mangementforschung, Vol. 3. W.H. Staehle and J. Sydow (eds.), 157-201. Berlin/New York: Walter De Gruyter.

Miner, A.S., and P. Anderson

1999 'Industry and population-level learning: Organizational, interorganizational, and collective learning processes' in Advances in strategic management, Vol. 16. A.S. Miner and P. Anderson (eds.), 1-30. Stamford, CN: JAI Press.

Nachum, L., and D. Keeble

1999 'Neo-Marshallian nodes and global networks: The global and the local in the media clusters of Central London'. Working paper, Centre for Business Research, Cambridge University.

Ocasio, W.

1999 'Institutionalized action and corporate governance: The reliance on rules of CEO succession'. Administrative Science Quarterly 4/3: 532-562.

Orrù, M., N.W. Biggart, and G.G. Hamilton 1991 'Organisational isomorphism in East Asia' in The new institutionalism in organizational analysis. W.W. Powell and P. DiMaggio (eds.), 361-389. Chicago: University of Chicago Press.

Phillips, M. E.

1994 'Industry mindsets. Exploring the cultures of two macro-organizational settings'. Organization Science 5/3: 384-402.

Podolny, J.M.

1993 'A status-based model of market competition'. American Journal of Sociology 98: 829-872.

Porac, J.F., H. Thomas, and C. BadenFuller

1989 'Competitive groups as cognitive communities: The case of Scottish knitwear manufacturers'. Journal of Management Studies 26/4: 397-416.

Porter, M.E.

1980 Competitive strategy. New York: Free Press. 
Powell, W.W.

1991 'Expanding the scope of institutional analysis' in The new institutionalism in organizational analysis. W.W. Powell and P. DiMaggio (eds.), 183-203. Chicago: The University of Chicago Press.

Powell, W.W., K.W. Koput, and L. SmithDoerr

1996 'Interorganizational collaboration and the locus of innovation: Networks of learning in biotechnology'. Administrative Science Quarterly 41: 116-145.

Robins, J.A.

1993 'Organization as strategy: Restructuring production in the film industry'. Strategic Management Journal 14: $103-118$

Scott, A.J.

1996 'The craft, fashion, and cultural products industries of Los Angeles: Competitive dynamics and policy dilemmas in a multi-sectoral imageproducing complex'. Environment and Planning $C$ 13: 97-124.

Scott, W.R.

1994 'Conceptualizing organizational fields. Linking organizations and societal systems' in Systemrationalität und Partialinteresse. H.-U. Derlien, U. Gerhardt, and F.W. Scharpf (eds.), 203-221. BadenBaden: Nomos.

Scott, W.R., and J.W. Meyer

1991 'The organization of societal sectors: Propositions and early evidence' in The new institutionalism in organizational analysis. W.W. Powell and P. J. DiMaggio (eds.), 108-140. Chicago: University of Chicago Press.

Sieber, P.

1998 Virtuelle Unternehmen in der ITBranche. Bern: Haupt.

Spender, J.-C.

1989 Industry recipes. Oxford: Basil Blackwell.

Stinchcombe, A. L.

1959 'Bureaucratic and craft administration of production: A comparative study'. Administrative Science Quarterly 4: 168-187.
Storper, M.

1989 'The transition to flexible specialisation in the US film industry: the division of labour, external economies, and the crossing of industrial divides'. Cambridge Journal of Economics 13/3: 273-305.

Storper, M., and S. Christopherson

1987 'Flexible specialization and regional industrial agglomerations: The US film industry'. Annals of the Associations of American Geographers 77/1: 104-117.

Sydow, J., and A. Windeler

1998 'Organizing and evaluating interfirm networks - A structurationist perspective on network processes and effectiveness'. Organization Science 9/3: 265-284.

Sydow, J., and U. Staber

2002 'The institutional embeddedness of project networks: The case of content production in German television'. Regional Studies 36/3, in print.

Tebert, $\mathrm{M}$.

2000 'Erfolg durch Qualität'. Mediaperspektiven 2: 85-93.

Tempest, S., K. Starkey, and C. Barnatt

1997 'Diversity or divide? In search for flexible specialization in the UK television industry'. Industrielle Beziehungen 4/1: 38-57.

Thornton, P.H., and W. Ocasio

1999 'Institutional logics and the historical contingency of power in organizations: Executive succession in the higher education publishing industry, 1958-1990'. American Journal of Sociology 105/3: 801-843.

Windeler, A.

2001 Unternehmungsnetzwerke. Konstitution und Strukturation. Wiesbaden: Westdeutscher Verlag.

Windeler, A., A. Lutz, and C. Wirth 2000 'Netzwerksteuerung durch Selektion - Die Produktion von Fernsehserien in Projektnetzwerken' in Steuerung von Netzwerken. J. Sydow and A. Windeler (eds.), 234-251. Wiesbaden: Westdeutscher Verlag. 